\title{
SOME OF THE IMMUNOGENETICS ASPECTS OF AGING
}

\author{
Bushra N. Al Hadra \\ Department of Clinical Immunology, \\ Medical University - Sofia
}

\section{Summary}

The human life span could be influenced by the combined effect of environment, lifestyle, and genetic factors. Twin and family studies suggest that our genes control up to $25 \%$ of the lifespan. The aging immune system undergoes ageassociated changes at multiple levels, resulting in a gradual loss of its ability to protect the organism against infections, low vaccine responses, and an increased probability of developing autoimmune diseases and malignancies. The highly polymorphic HLA complex is one of the major gene candidates associated with aging due to its crucial role in developing adaptive immunity and protecting the organism. Most of the data available have so far demonstrated a positive association with healthy aging for HLA alleles/haplotypes as protective against malignancies, autoimmune diseases, and conferring better control and response to infections.

One of aging's main manifestations is the chronic, low-grade inflammatory state observed in older people, caused by an imbalance between pro- and anti-inflammatory cytokines. In general, it is has been agreed that longevity is related to antiinflammatory genotype profiles. With advanced age, changes also occur in the B cell repertoire, which significantly affects the humoral immunity and leads to inadequate responses to infections and vaccines in the elderly. New genetic biomarkers associated with aging are being explored and discovered, contributing to a better understanding of the molecular processes underlying the immune dysfunction related to aging and developing strategies for rejuvenating the immune system based on immune-risk phenotypes.

Keywords: Ageing, HLA, cytokines, B cells

\section{Introduction}

The population worldwide is rapidly aging. A century ago, communicable diseases killed thousands of people, and often at very young ages. Today, many more people live longer due to the discovery and dissemination of today's essential public health - hand washing, refrigeration, sterile working environment, etc. Simple things like clean water and sanitation helped humans dramatically change the conditions they live in, enabling people to experience a much longer life. Nowadays, living to the age of sixty is something that most of us could expect, and it is predicted that by 2050 , the number of people aged 60 and above will be 2 billion in total ( $22 \%$ of the global population), 
as compared to 900 million in 2017 (12.3\%), which is almost double [1]. Living longer has both challenges and opportunities. From a public health perspective, older people are a critical risk factor for various age-associated diseases, including neurodegenerative diseases, malignancies, autoimmune and metabolic disorders. Studying the underlying cellular and molecular mechanisms that deteriorate with age and lead to increased fragility and morbidity in the elderly is critical for a better understanding of the healthy aging process.

Aging is a multifactorial process leading to the gradual deterioration of multiple organ systems. The aging immune system undergoes age-associated changes at multiple levels, resulting in a gradual loss of its ability to protect the organism against infections, inadequate vaccine responses, and an increased probability of autoimmune diseases and malignancies. All of these changes lead to higher morbidity and mortality rates in the elderly. The mechanisms underlying the age-related disorders are many and are not fully understood yet.

Many studies have investigated the role of the most polymorphic region known in the human genome - the HLA system (MHC), encoding molecules that play a major role in developing adaptive immunity. Most of the studies focus on classical HLA class I and class II genes, while the role of the so-called 'non-classical' HLA genes (MIC) is still unclear. HLA distribution has been analyzed in several populations worldwide, and the results are contradictory, suggesting that the HLA / life expectancy association is populationspecific. Some data indicate a possible association of HLA class II specificities with life expectancy, but clear evidence is still lacking [2]. Longevity is also associated with polymorphisms in cytokine genes that correlate with different cytokine expression levels and thus modulate the immune response. In particular, polymorphisms associated with increased anti-inflammatory cytokines are thought to be associated with successful aging. Conversely, a high incidence of proinflammatory polymorphisms/haplotypes increases the susceptibility to age-associated diseases.

Another aspect of the immune system needed for understanding the overall aging phenotype is the impact of age on the production and development of B cells, which play a central role in constructing and maintaining humoral immunity. The B-cell repertoire diversity is crucial to provide a sufficient number of antibodies needed for recognizing the broadest possible spectrum of exogenous antigens and because $\mathrm{B}$ cells are essential mediators of the immune response. Age-associated changes in the B-cell repertoire can generally be summarized in the following groups: clonal B-cell expression in the absence of exogenous antigen, resulting in disruption of B-cell diversity; reduced expression of genes critical for B cell production and differentiation; reduction in gene products vital for class switching and somatic hypermutation, affecting the efficacy of the humoral immune response; impaired mechanisms of positive and negative selection, resulting in the deterioration of the correct process of regulation and elimination of autoreactive and non-efficient antibodies.

Together with the microenvironmental and homeostatic changes that occur in aged individuals, all these changes cause the general aging profile. As a field of science, the aging of the immune system is attracting more and more interest in both the scientific and healthcare sectors. Although immunosenescence is a relatively young science, to date, much has been discovered and described. Moving from the study's descriptive phase to finding causation links and applying them into therapies is crucial for avoiding diseases occurring with advancing age and maintaining optimal physiological and immunological functions for successful aging.

\section{HLA polymorphism and association with aging}

The major histocompatibility complex (MHC), located on the short arm of human chromosome six (6p21) [3], is composed of a large set of polymorphic genes whose products play a crucial role not only in tissue compatibility but also in the immune response, providing protection of the body against pathogens and tumorigenesis. The first MHC products were found on the surface of white blood cells (leukocytes), and therefore, human MHCs are called human leukocyte antigen (HLA). The MHC gene family is divided into three classes: MHC class I, MHC class II, and MHC class III. The MHC class I (HLA-A, -B, and -C) and class II (HLA-DR, 
-DQ, and -DP) genes encode antigen-presenting molecules that bind short peptides and stimulate CD8 + and CD4 + T cells, respectively [4]. MHC class III encodes a diverse group of molecules that perform different immune functions in the body [4]. Antigen-presenting MHC molecules are known as classic MHC molecules.

In the last decades, several studies have examined the impact of HLA genes on life expectancy [5-16] due to the significant degree of polymorphism of these genes and their prominent role in modulating the immune response. Certain HLA specificities have a different distribution in elderly and young individuals. The data from different population studies on the association between longevity and HLA are generally difficult to interpret and are discordant due to the different genetic background of the populations inhabiting geographical areas with different environmental factors. On the other hand, major methodological problems like age, sample size limits, studding of particular HLA loci, different typing approaches, and/or different selection criteria further complicate the interpretation of the results. Aging is a multifactorial process, which could be influenced by genetics and environmental and lifestyle factors. For instance, Sardinian and Okinawa populations, well known for their longevity members and also referred to as 'Blue Zones' inhabitants, share a typical lifestyle and are isolated populations with specific gene pools. A study, investigating the HLA allele distribution among different regions in Italy found that Sardinians and the inhabitance of distant regions like northern and southern Italy carry out statistically different alleles and haplotypes [17].

One investigation on the association between HLA allele distribution and longevity in Sardinian centenarians has found that HLA-DRB1*15 alleles have non significantly increased frequency in centenarians ]16]. Interestingly, HLA-DRB $1 * 15$ is one of the major genetic factors associated with multiple sclerosis (MS), including one Italian multigenerational MS family study [18-21]. On the other hand, there are pieces of evidence for the protective effect and better response to HBV antigens in carriers of that allele [22-24]. In Okinawan centenarians, increased frequencies of the following class II alleles were observed:
DQB1*05:03, DQA1*01:01; *05, DRB1*01:01, $* 12: 01$ and *14:01 [8]. Furthermore, in another study, it was confirmed that siblings of Okinawan centenarians had an increased chance of reaching 90 years compared with the general population [25]. These data further emphasize the population specificity of HLA allele distribution and the significant familial component of human longevity. The contradictory data from the different MHC-longevity association studies might be due to the interaction of different factors like lifestyle, environmental factors, sex, genetic heterogeneity of the population, and different linkage in different cohorts.

HLA-haplotypes can explain some misinterpreted associations with specific HLA alleles due to linkage disequilibrium. For example, narcolepsy was firstly associated with HLA-DRB1*15, and later it was found that the actual culprit was the HLA-DQB1*06:02 allele in the haplotype [26]. Despite the significant importance of studying haplotype associations for more comprehensible results, relatively few studies have examined HLA haplotypes' role on life expectancy [27-30]. The common for Caucasians haplotype 8.1 AH (A1-C7-B8-DR3) or parts of this haplotype are also associated with various autoimmune diseases in healthy subjects with immune system dysfunctions and T-cell mediated immunity in particular. Two studies on Irish and French populations found a significant increase of A1B8Cw7DR3 haplotype in nonagenarian men [27,31]. These findings suggest that there might be some gender-specific differences in lifespan that could be influenced by specific biological factors like X-linked genes and sex hormones, and/or different social and lifestyle factors. Therefore, the TI $\rightarrow \mathrm{T} 2$ shift in the immune response typical of the $8.1 \mathrm{AH}$ seems beneficial to longevity in older men and might be considered a marker of successful aging.

On the other hand, this haplotype might be a risk factor for women, who are generally more susceptible to autoimmune diseases [32]. An HLA allele assumed to have a positive association with longevity in females is DR11, which is observed with higher allele frequency in older women in two Caucasian populations and Mexicans [5,6,9]. In one of these studies on the French population [9], another genderspecific difference was observed for the DR7 
Table 1. Summary from different population studies on HLA and longevity

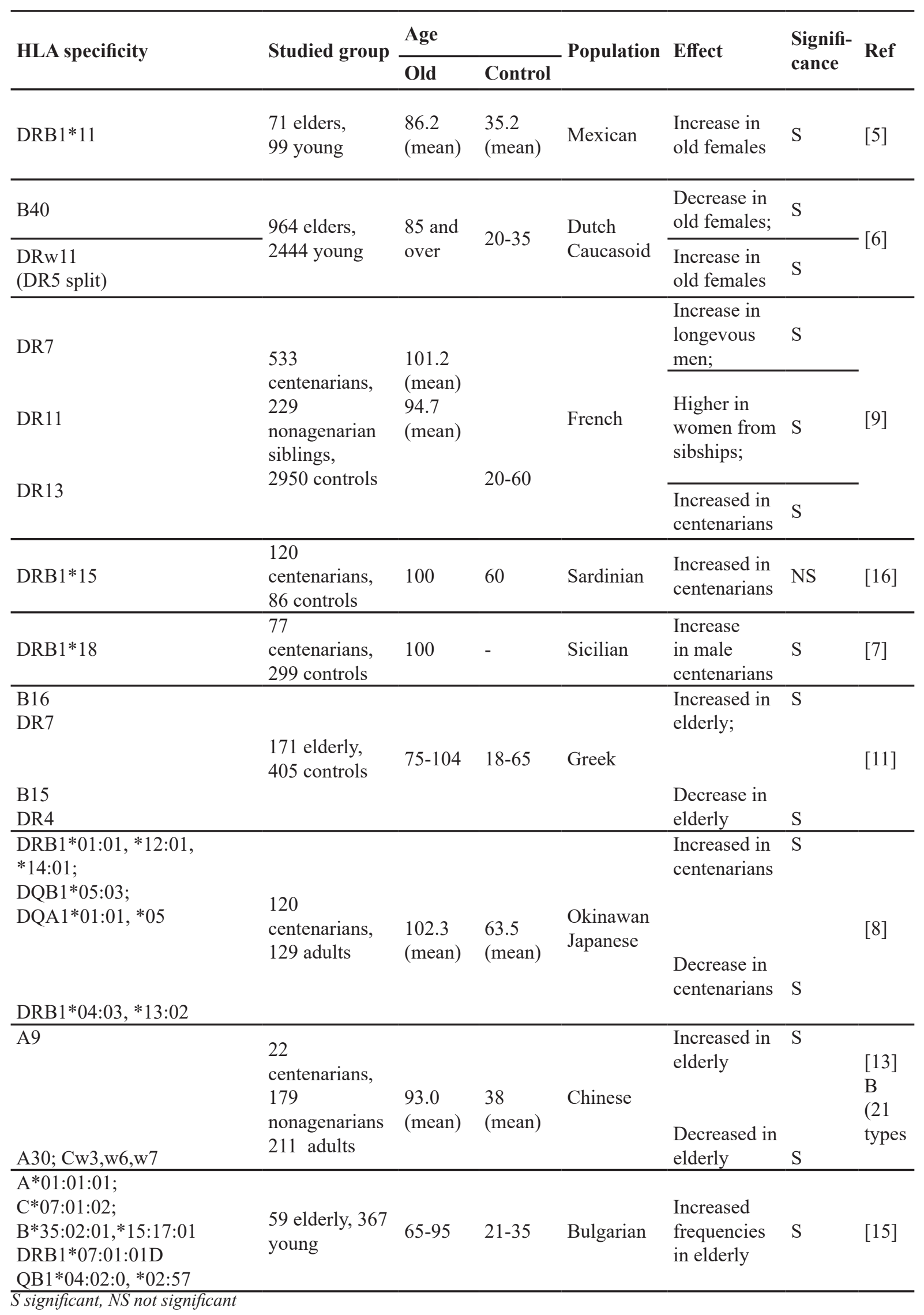


allele, which is increased in longevous men. DR7 was also observed with increased frequency in elderly Greeks [11]. Interestingly, although there is no evidence for DR7 -disease association for these Greeks, the antigen's specificity is linked with susceptibility to viral infections [33-36] and autoimmune disease [37-39] in several populations. On the other hand, the increased frequency of DR 11 in elderly females corresponds to this allele's protective effects in infectious diseases [36,40-42].

When summarizing data from different population studies, mainly HLA class II alleles occur at a higher frequency in elderly subjects. (Table 1)

That could be explained by HLA class II molecules' role in antigen presentation and the induction of cytotoxic CD8+ $\mathrm{T}$ cell response. Besides, HLA-DR and - DQ are well-preserved and play a role in a variety of age-related diseases. In a recent study of long-lived Chinese individuals, four SNPs of the HLA-DQB1 locus were identified, associated with longevity and lipid homeostasis [43]. DRB1*18 alleles were found to be significantly more frequent in Sicilian centenarians [7]. The HLA allelic distribution was also analyzed in a collaborative study on four populations (Bulgarians, Romanians, Italians, and Kuwaiti). By applying NGS approaches, a statistically significant increase of several HLA class II alleles was detected in elderly Bulgarians: DRB1*07:01:01, *04:10:01; DQB1*04:02:01, *05:01:04, *02:57 and DQA1*03:03:01 [15].

Interestingly, in different populations, some of these alleles are described as predisposing for infection, autoimmune diseases, and allergy: DQB1*05:01 is associated with the active state of hepatitis B and autoimmune disease [44,45]. DQB1*04:02 in Japanese is associated with autoimmune polyendocrine syndrome type III [46], and DRB1*07:01 - with asparaginase hypersensitivity [47]. Another interesting observation in a very recent study in Japan [48] is that HLA-DRB1*04:10-HLA-DQB1*04:02 haplotype is significantly increased in patients with Moyamoya disease and that patients caring DRB1*04:10 allele are more likely to develop autoimmune diseases. On the other hand, the increased frequency of HLA-DRB $1 * 07$ in elderly Bulgarians corresponds with the previously reported positive association of these alleles with longevity in the Greek and French populations. All these data highlight the need to clarify the impact of the genetic background regarding HLA and life expectancy. Identifying population-specific alleles and haplotypes trough, which can identify individuals at high risk of developing age-associated diseases or disabilities, would lead to the development of strategies for rejuvenating the immune system based on immune-risk phenotypes.

However, despite the prevalence of HLA class II alleles, there are also several HLA class I alleles associated with longevity: in adult Italians (high frequency of A31, B7, and Cw7) [49], Greeks (increased frequency of B16 and reduced B15) [11], Chinese (high frequency of A9 and low of A30, Cw3, w6, w7) [13], elderly Dutch women (reduced B40 frequency) [6] and in elderly Bulgarians (increased frequency of $A^{*} 01: 01: 01$; C*07:01:02; B*35:02:01,*15:17:01).

Given the vital role of HLA in modulating the immune response, it is suggested that survival and longevity might be positively associated with selecting HLA alleles and haplotypes conferring disease resistance or susceptibility. Several studies from the last decades have investigated these possible associations, but a definite conclusion is still lacking. To further clarify the role of HLA in longevity, studies on larger sample groups with defined general selection criteria in different ethnic populations are of great importance. Therefore, HLA alleles/ haplotypes could be informative immunogenetic markers for developing strategies for maintaining optimal immunological functions in elderly individuals.

\section{Polymorphisms in cytokine genes and their association with successful aging}

Aging is characterized by an imbalance between pro-and anti-inflammatory cytokines, leading to chronic, low-grade inflammatory conditions in aged organisms, contributing to the onset of major age-related diseases such as cardiovascular diseases, neurodegeneration, osteoarthritis and osteoporosis, and diabetes. Human longevity correlates with optimal immunological functioning, and due to the essential role of cytokines in regulating the immune system, gene polymorphisms responsible for different 
cytokine production patterns are also associated with longevity. Genotypes correlating with elevated levels of proinflammatory cytokines are generally negatively associated with longevity. Although some researchers have demonstrated an association between cytokine polymorphism with longevity [14,30,50-55], the data collected are very controversial, which warrants further research into this field. Several pro-and antiinflammatory cytokines have been investigated, but one of the main culprits associated with aging are IL- 6, TNF- $\alpha$, IFN- $\gamma$, IL-10, and TGF- $\beta$.

IL-6, also known as stem cell-stimulating factor, interferon $\beta-2$, or $\mathrm{B}$ cell differentiation factor, and "gerontologist's cytokine," is a multifunctional cytokine and significant factors involved in the acute phase response and inflammation [54,56,57]. In three Italian studies of the very old, increased level of IL- 6 production was associated with a greater risk of morbidity and mortality [58-60]. Three promoter polymorphisms, $-174 \mathrm{G}>\mathrm{C},-572 \mathrm{G}>\mathrm{C}$, and $-597 \mathrm{G}>\mathrm{A}$, are associated with different plasma levels of IL-6 [61], of which the most commonly studied SNP is $-174 \mathrm{G}>\mathrm{C}$. In several studies- three of which performed on the Italian population and one in Brazilian, it has been found that the - 174 GG genotype, correlating with high-producing levels of IL-6, increases the risk of development of cardiovascular diseases and reduces the chance of reaching old age [62-65]. Contradictory to these data, in elderly females from Sweden, the GG genotype is associated with a higher life expectancy [66]. On the other hand, studies on populations such as Finnish [67], Bulgarian [14], and Sardinian [52] did not establish a significant association between IL-6 polymorphism and life expectancy. Furthermore, in a meta-analysis of eight case-control studies performed on European populations, no significant association between the IL-6 polymorphism and longevity was found, except for those in Italian centenarians for whom IL-6 -174GG genotype was negatively associated with longevity and reduced the chance of reaching old age for males with that genotype [68]. These conflicting data suggest that the effect of this polymorphism is populationspecific and dependent on the interaction of genetic background and environmental factors.

The interleukin-6 expression is strongly dependent on TNF- $\alpha$. The TNF- $\alpha$ gene is part of the HLA class III region located between the HLA-B and HLA-DR loci [69]. Its gene product is involved in systemic inflammation and the acute phase reaction, playing a significant role in providing resistance to infections and cancer through inducing cell apoptosis and necrosis [61]. Similar to IL-6, TNF- $\alpha$ also shows agedependent changes in the levels of expression. A promoter polymorphism in the TNF- $\alpha$ gene at position 308 consisting of substitution of guanine with adenine results in strong activation of the transcription process and, therefore, in high expression levels of TNF- $\alpha$ [70]. In the study of Cederholm et al. (2007 in a Swedish population, similarly to the observation for IL-6, the high producing A allele of TNF-a -308 correlates with prolonged survival in women [66].

On the other hand, in Danish centenarians, the AA genotype correlated with higher mortality, and it was suggested that the GA genotype could be protective against agerelated neurodegenerative disorders [71]. In several studies in North American, Danish, and Dutch elderly, the increased serum level of the proinflammatory cytokine correlates with increased likelihood for respiratory and heart diseases and mortality [72-76]. In contrast to Giovannini et al. (2011) finding for IL-6 in Italian elderly subjects, no significant association was found between TNF- $\alpha$ levels and mortality [60]

IFN $\gamma$ is a type II interferon, playing a critical role in modulating the immune system and mediating the antiviral and antibacterial immunity. Its pleiotropic immunological functions are characterized by its ability to orchestrate the immune system by upregulating the expression of $\mathrm{MHC}$, thus enhancing the antigen presentation, keeping the Th1/Th2 balance, promoting the activation and differentiation of cells from the innate and adaptive immunity such as $\mathrm{T}$ cells, B cells, macrophages, NK cells, and other cell types [77]. In agreement with the inflamm-aging hypothesis, Zanni et al. (2003) found that in all CD8+ T cell subsets from elderly individuals, there was a significant increase of the intracellular levels of all the studied type 1 cytokine - IFN $\gamma$, IL-2, and TNF- $\alpha$ [78]. When investigating the effect of aging on the intracellular levels of type 1 and 2 cytokines in $\mathrm{CD} 4+\mathrm{T}$ cell subsets, it was found that the 
number of IFN- $\gamma$ positive and TNF- $\alpha$ positive activated/memory CD4+ subset significantly decrease in elderly individuals [79]. This finding also supported the hypothesis for reduced type 1 cytokine activity in old subjects. In Sicilian nonagenarians, no changes in IFN $\gamma$ plasmatic levels were observed in elderly individuals [58]. In Irish elderly and Sardinian centenarians, no difference in IFN- $\gamma$ allele polymorphism frequencies was found when compared to healthy young controls [52,53]. The gender-specific association was found in Italian centenarians; the $+874 \mathrm{~T}$ allele associated with high IFN $\gamma$ production was detected with a decreased allele frequency in female centenarians compared to young women [80). This is interpreted in the context that reduced frequency of genotypes conferring decreased levels of proinflammatory cytokines is beneficial for successful aging.

The polymorphism in cytokine genes is a perfect example of the pleiotropic effects of some genes that are beneficial early in life, but their late-life effects are damaging for the organism. The proinflammatory immune response, which protects the individual from the harmful effect of pathogens and infections in early life, become detrimental in the post-reproductive period of life [54]. Chronic low-grade inflammation result of the constant antigenic presentation of persistent infection leads to severe tissue damages without any symptoms for years. Besides, individuals affected by age-associated diseases such as atherosclerosis, diabetes, obesity, sarcopenia, and Alzheimer's disease share the common condition of chronic inflammation [81]. There is a hypothesis that long-lived people may deal with inflammation through a well-balanced, antiinflammatory response [4]. Given the critical role of IL-10 in limiting the inflammatory response [82], many studies have focused on examining its role in successful aging. IL-10 haplotypes $-1082 \mathrm{G},-819 \mathrm{C},-592 \mathrm{C}$ associated with high cytokine expression levels have been found with statistically significant high incidence in healthy adult subjects in the Bulgarian population [83]. A high incidence of IL-10 - 1082G homozygous genotype has been observed in Italian centenarians [51] and long-lived men from the Jordanian population [55]. A study in the Italian population has established that high IL-10 levels are protective against myocardial infarction [84], thus supporting the possible role of IL-10 production in longevity. The frequency of high producer IL-10 polymorphism was not increased in elderly individuals from Irish, Finnish and Sardinian populations $[53,85,86]$. Therefore, the data collected from various studies on polymorphisms in cytokine genes support the hypothesis that longevity is most likely associated with anti-inflammatory status, and the cytokine/longevity associations have a population-specific distribution. The balance between proinflammatory and anti-inflammatory helps to avoid chronic diseases or delays onset and leads to longevity.

Transforming growth factor-beta (TGF- $\beta$ ) is a potent pleiotropic cytokine that plays an essential role in inflammation suppression and has been linked to tumor growth regulation $[87,88]$. Few studies have found an association between TGF- $\beta$ and longevity. In Swedish and Italian long-lived individuals, a significant increase in the serum level of TGF- $\beta$ was found, compared to healthy young $[89,90]$. In a study on Japanese elderly, a correlation between TGF- $\beta 1$ levels and gender, age, and lifestyle was found [91]. Interestingly, the authors observed that, with age, the serum levels of TGF- $\beta 1$ decrease, which decrease corresponded to another study in the Japanese population, where TGF- $\beta 1$ levels were significantly increased in children's sera, compared to adults [92]. Furthermore, the same study of Lin et al. (2009) found that males consuming tobacco and alcohol have an increased level of TGF- $\beta 1$ in their sera, but for confirmation of those results longitudinal study should be performed.

Pro- and anti-inflammatory cytokines are involved in the intricately regulated inflammation process that could be influenced by gene polymorphisms, environment, and lifestyle factors. To determine the exact immunogenetic basis of long-life, additional analyses are necessary that should encompass extended haplotypes, including several polymorphisms in cytokine genes, as well as haplotypes consisting of SNPs in different cytokine genes. Epigenetic studies on cytokine and chemokine gene expression in adult individuals with different immunogenetic profiles will contribute to a better understanding of the aging process [2]. 
Age-associated changes in B-cell repertoire and $B$-cell receptor (BCR)

With advancing age, several changes in the immune system occur. B cells play a central role in constructing and maintaining acquired immunity through the generation of antibodies, antigen presentation, and immune regulatory functions. "B cell repertoire" is a concept that can be considered at both cellular level, where there are different stages of B-cells development, and molecular level, where the immunoglobulin gene rearrangement determines the specificity of each B-cell [93]. Many mechanisms (random rearrangement of the variable immunoglobulin gene segments, non-template nucleotides addition, exonuclease activity; random combination of heavy and light chains; somatic hypermutation, and class switching) generate a wide variety of antigenic specificities in order to ensure that there is an antigen-binding site to fit any exogenous antigen. $\mathrm{B}$ cells are continuously generated in the bone marrow from hematopoietic stem cells (HSCs) in adults. The general phenotype of the aging B-cell populations results from the so-called "snowball" effect, in which abnormalities in critical early events in B-cell development lead to escalating consequences in cell differentiation [94]. Critical factors for understanding the age-associated changes in humoral immunity determine how the expression of essential gene products is regulated and how the deterioration of the bone marrow's age-related microenvironments affects the selection processes and homeostasis of the pre-B cell populations. To date, there are many pieces of evidence for the significant changes in the functional and developmental features of B cell repertoire with age (Figure 1).

The aging immune system is associated with decreased B cell production [95], but the total count of peripheral B cells is relatively stable during life [96]. Aging leads to a gradual loss of early B-lineage precursors, which could be associated with epigenetic dysregulation in HSCs and reduced expression of the transcription factor E2A, which is essential at several stages B-lymphocyte differentiation, including the generation of pro-B cells [97]. The expressions of genes such as RAGs (recombination-activating genes) [98] and lambda-5 $(\lambda-5)$, which are vital for passing through pro- and pre-B cell stages, are also diminished [99-101].

The B-cell repertoire diversity decreases with age [102], and this decrease leads to increased susceptibility of older people to infectious diseases, malignancies, and inadequate response to vaccinations. One way of evaluating the repertoire diversity of antibodies is by spectratyping analysis of the CDR3 regions, thus determining a large set of variable domains of the heavy chains of the immunoglobulins (IGHV). Such a study has shown a significant

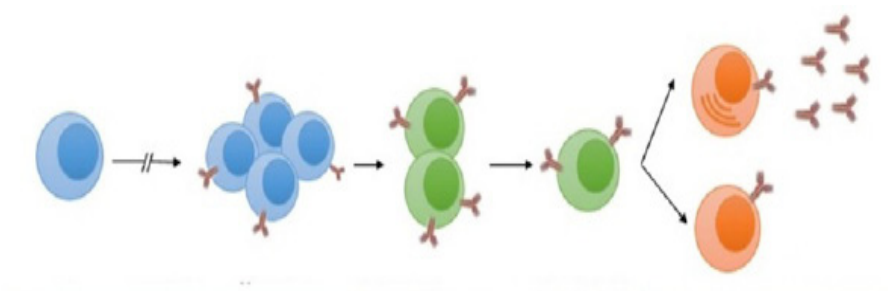

\begin{tabular}{|c|c|c|}
\hline Bone marrow progenitors & Peripheral pools & Antigen-experienced pools \\
\hline $\begin{array}{l}\text { - HSC changes } \\
\text { - Decreased production } \\
\text { of B cells } \\
\text { - Reduced BM output }\end{array}$ & $\begin{array}{l}\text { - Altered pool size } \\
\text { - Reduced BCR diversity } \\
\text { - Altered homeostatic } \\
\text { conditions } \\
\text { - Increased cancer } \\
\text { chance }\end{array}$ & $\begin{array}{l}\text { - Poor memory } \\
\text { responses } \\
\text { - Inefficient responses to } \\
\text { vaccinations and } \\
\text { infections } \\
\text { - Increased rates of } \\
\text { autoimmunity and } \\
\text { tumors }\end{array}$ \\
\hline
\end{tabular}

HSC: hematopoietic stem cell; BCR: B-cell receptor; BM: bone marrow (adapted from Cancro MP et al. (2009) (94)).

Figure 1. Age-related changes in B cell repertoire 
decrease in peripheral blood repertoire diversity in adult peripheral blood [102], correlating with poor health. The reduction in the number of potential antigenic specificities deteriorates the strength of the humoral response against pathogens. At the same time, increased levels of autoantibodies and cross-reactivity responses following antigen stimulation are observed in older adults [103]. Therefore, changes in the repertoire, along with other intracellular and microenvironment changes, are the basis for the developmental and functional disorders in B-cells. Although some features of the B cell repertoire do not change in adulthood, it is has been found that there is a tendency for accretion of highly mutated $\operatorname{IgM}$ and $\operatorname{IgG}$ genes and clonal expansion of B cell populations in older people [104]. Such tendencies are consistent with the suggestion of persistent antigen stimulation in elderly subjects. Chronic infections such as CMV and EBV can affect the presence of clonal expansions (EBV) or the levels of mutation of antibodies (CMV) [104]. There are indications that some age-related changes are class-specific [93]. In particular, while in normal conditions, IgM and IgG antibodies' relative ratio changes upon challenging the immune system, which is not always observed in adults [105]. Other age-associated changes are impaired $\operatorname{IgM}$ and $\operatorname{IgA}$ response after immunization with pneumococcal vaccine and expansion of B cells with more extended CDR3 regions, suggesting a disadvantage of these features in initiating appropriate immune responses [106]. It is also hypothesized that there is a difference in the use of $\operatorname{Ig}$ genes during aging. Increased use of $\operatorname{Ig} \mathrm{A} 2$ rather than IgA1 and of IgG2 over IgG1/IgG3 in CD27+ memory cells is observed in the elderly [107]. IgG2 B cell subclasses are involved in the responses to polysaccharides, suggesting that older people's B-cell repertoire is selected in a T-independent way [93].

Alterations in the physiochemical characteristics of the $\mathrm{CDRH} 3$ region resulting from mutations in the immunoglobulin gene repertoire could affect BCR- binding ability and, therefore, the selection processes [108]. CDRH3 has a crucial role in forming the B cell receptor's antigen-binding site and is most likely to undergo a positive or negative selection. Naive $\mathrm{B}$ cells are found with shorter and therefore less hydrophobic CDRH3 region than immature B cells in bone marrow [109], suggesting that more extended CDRH3 regions are subjected to an adverse selection. The larger size of the CDRH3 region in adults is an indication that negative selection processes are likely to be less effective with advancing age [104,107]. The long CDR3 regions might result from the incorporation of long D genes or the use of several D gene segments, and/or of the addition of large nontemplate $(\mathrm{N})$ regions [110]. Interestingly, long Ig CDRH3s and positively charged amino acids are characteristic of autoreactive antibodies [109], consistent with the higher levels of autoreactive antibodies observed in older individuals. Understanding the underlying mechanisms of selection and how they affect the repertoire and performing comparative analyzes of repertoires between different age groups will help elucidate age-associated changes in B-cell function that contribute to immunological aging.

\section{Conclusion and prospects}

Life expectancy is a topic of interest to humanity for thousands of years, beginning with philosophers who speculated about the extent to which it is determined by fate [111]. To date, twin and family studies suggest that the heritability of human lifespan is up to $25 \%$ [2]. The rate of aging in distinct ethnic groups is not equal due to genetic heterogeneity and the impact of various environmental factors. The aging process is characterized by a progressive deterioration in the functions of different organs and organ systems in the human body. In the last decades, immunosenescence as a science field has been attracting more interest, not only in the scientific but also in the healthcare sectors. The aging immune system undergoes age-associated changes at multiple levels, resulting in a gradual loss of its ability to protect against infections, inadequate vaccine responses, and increased probability of the development of autoimmune diseases and malignancies. All of these changes are leading to higher rates of morbidity and mortality in the elderly. The mechanisms underlying the age-related disorders are many and are not fully understood yet. HLA is one of the major gene complexes associated with aging due to its central role in developing 
adaptive immunity. Several population studies have investigated this possible association, but a definite conclusion is still lacking, mainly because of the contradictions between the data obtained. That could be attributed to several difficulties in conducting this type of study. Firstly, different methodological techniques are used for HLA typing, making it difficult to compare the data from different studies. Secondly, studies on larger samples and different ethnic groups are needed to clarify the impact of the genetic background regarding HLA and life expectancy.

Furthermore, investigating the role of extended HLA haplotypes on life expectancy rather than focusing on specific HLA loci and using general selection criteria for the subjects included in the study. Most of the data available so far have demonstrated a positive association with healthy aging of HLA alleles/haplotypes as protective against malignancies, autoimmune diseases, and conferring better control and response to infections. Due to cytokines' significant role in modulating immune responses, it has been hypothesized that cytokine gene polymorphisms responsible for different cytokine production patterns could also be associated with longevity. In general, based on the collected data from different studies, it is agreed that longevity is related to anti-inflammatory genotype profiles. Although the aging process in its main part is under genetic control, there is an impact of diverse environmental factors such as infections. Another aspect of the immune system that is affected by advanced age is humoral immunity. Many age-associated changes in B cell repertoire have been reported in aged mice and humans, including oligoclonal expansion of $\mathrm{B}$ cells, $\mathrm{T}$-independent Ig production, reduced $\mathrm{BCR}$ diversity, low-affinity, and low titer antibodies, generation of more auto-reactive antibodies, among others. Such defects significantly affect humoral immunity and lead to the main manifestations of aging - inadequate response to infections and vaccines.

New biomarkers are continually being explored for a better understanding of the processes underlying immune dysfunction and senescence. The candidate genes influencing longevity could be divided into the following categories: immune-related factors, stress elements, mediators of metabolism, genes involved in the DNA repair mechanisms, cellular proliferation, and mitochondrial haplogroups [2]. Through those biomarkers, individuals at high risk for developing age-related disorders could be identified, and strategies based on immunerisk phenotypes can be applied to rejuvenate the immune system. Given the growing average age of the population, a transition from description to finding causative effects and applying them in therapies is crucial to maintain optimal physiological and immunological functions in the elderly and successful aging.

\section{References}

1. World health organization. Ageing and health. A review [online]. 2018 [cited 2018 Feb 5] Available from: URL: https://www.who.int/ news-room/fact-sheets/detail/ageing-andhealth. 2018;2018.

2. Naumova E, Ivanova $M$, Pawelec $G$. Immunogenetics of ageing. Int J Immunogenet. 2011;38(5):373-81.

3. Choo SY. The HLA system: Genetics, immunology, clinical testing, and clinical implications. Yonsei Med. J. 2007;48:11-23.

4. Pallavi P, Vijaya B, Rashmi B K. Recipient Hemovigilance Study in a University Teaching Hospital of South India: An Institutional Report for the Year 2014-2015. Glob J Transfus Med. 2017;2(2):124-9.

5. Soto-Vega E, Richaud-Patin Y, Llorente L. Human leukocyte antigen class I, class II, and tumor necrosis factor-alpha polymorphisms in a healthy elder Mexican Mestizo population. Immun Ageing. 2005;2:13.

6. Lagaay AM, D Amaro J, Ligthart GJ, Schreuder GM V, Rood JJ HW. Longevity and heredity in humans. Association with the human leucocyte antigen phenotype. Ann N Y Acad Sci. 1991;621:78-89.

7. Listì F, Caruso C, Colonna-Romano G, Lio D, Nuzzo D, Candore G. HLA and KIR Frequencies in Sicilian Centenarians. Rejuvenation Res. 2010;13(2-3):314-8.

8. Akisaka M, Suzuki M, Akisakal M, Suzuki M. Molecular genetic studies on DNA polymorphism of the HLA class II genes associated with human longevity. Tissue Antigens. 1997;50(5):489-93.

9. Ivanova $\mathrm{R}$, Hénon $\mathrm{N}$, Lepage $\mathrm{V}$, Charron D, Vicaut E, Schächter F. HLA-DR alleles display sex-dependent effects on survival and discriminate between individual and familial 
longevity. Hum Mol Genet. 1998;7(2):187-94.

10. Lio D, Motta M, Franceschi C, Malaguarnera M, Candore G, Caruso C. Association between the MHC class I gene HFE polymorphisms and longevity: a study in Sicilian population. Genes Immun. 2002;20-4.

11. Papasteriades C, Boki K, Pappa H AS, Papasteriadis E EJ. HLA phenotypes in healthy aged subjects. Gerontology. 1997;43:176-81.

12. Takata H, Ishii T, Suzuki M, Sekiguchi S, Iri H. Influence of Major Histocompatibility Complex Region Genes on Human Longevity Among Okinawan-Japanese Centenarians and Nonagenarians. Lancet. 1987;330(8563):824-6.

13. Yong-Xing M, Yue Z, Zan-Shun W, Chuan-Fu W, Su-Ying C, Mao-Tong Z, et al. HLA and longevity or aging among Shanghai Chinese. Mech Ageing Dev. 1997;94(1-3):191-8.

14. Naumova E, Mihaylova A, Ivanova M, Michailova S, Penkova K, Baltadjieva D. Immunological markers contributing to successful aging in Bulgarians. Exp Gerontol. 2004;39(4):637-44.

15. Ivanova $\mathrm{M}$, Creary LE, Al Hadra B, Lukanov T, Mazzocco M, Sacchi N, et al. 17th IHIW component "Immunogenetics of Ageing" - New NGS data. Hum Immunol. 2019;(May 2018):111.

16. Ferlazzo V, Lio D, Mario G, Carru C, Listı F, Candore G, et al. Association between the HLADR alleles and longevity : a study in Sardinian population. Exp Gerontol. 2003;38:313-8.

17. Piazza A, Olivetti E, Rm G, Rendine S, Amoroso A, Barbanti M, et al. The distribution of HLA antigens in Italy. Gene Geogr. 1989;3(2-3):14164.

18. Bera O, Cabre P, Alizadeh M, Smadja D, Jugde F, Edan G, et al. Genetic and functional studies in multiple sclerosis patients from Martinique attest for a specific and direct role of the HLADR locus in the syndrome. Tissue Antigens. 2003;61:166-71.

19. Scholz EM, Marcilla M, Daura X, ArribasLayton D, James EA, Alvarez I. Human Leukocyte Antigen (HLA)-DRB1*15:01 and HLA-DRB5*01:01 Present Complementary Peptide Repertoires. Front Immunol. 2017; 8(August):1-12.

20. Handunnetthi L, Ramagopalan S V, Ebers GC. Multiple sclerosis, vitamin D, and HLADRB1*15. Neurology. 2010;74:1905-10.

21. Mosca L, Mantero V, Mantia L La, Marazzi MR. HLA-DRB1 * 15 association with multiple sclerosis is confirmed in a multigenerational Italian family. Funct Neurol. 2017;32(2):83-8.

22. Wang C, Tang J, Song W, Lobashevsky E, Wilson CM, Kaslow RA. VIRAL HEPATITIS
HLA and Cytokine Gene Polymorphisms Are Independently Associated With Responses to Hepatitis B Vaccination. Hepatology. 2004;39:978-88.

23. Yang G, Liu J, Han S, Xie H, Du R, Yan Y, et al. Association between hepatitis B virus infection and HLA-DRB1 genotyping in Shaanxi Han patients in northwestern China. Tissue Antigens. 2007;69:170-5.

24. Cheng YQ, Lin JS, Huang LH, Tian DY, Xiong P. The association of HLA-DRB1 allele polymorphism with the genetic susceptibility to liver cirrhosis due to hepatitis B virus. Chinese $\mathrm{J}$ Med Genet. 2003;20(3):247-9.

25. Willcox BJ, Willcox DC, He Q, Curb JD, Suzuki M. Siblings of Okinawan Centenarians Share Lifelong Mortality Advantages. J Gerontol. 2006;61(4):345-54.

26. Ellis MC, Hetisimer AH, Ruddy DA, Hansen SL, Kronmal GS, McClelland E, et al. HLA class II haplotype and sequence analysis support a role for DQ in narcolepsy. Immunogenetics. 1997;46(5):410-7.

27. Rea IM, Middleton D. Is the Phenotypic Combination A1B8Cw7DR3 a Marker for Male Longevity? J Am Geriatr Soc. 1994;42(9):97883.

28. Ross OA, Curran MD, Rea IM, Hyland P, Duggan O, Barnett CR, et al. HLA haplotypes and TNF polymorphism do not associate with longevity in the Irish. Mech Ageing Dev. 2003;124(4):563-7.

29. Scola L, Lio D, Candore G, Forte GI, Crivello A, Colonna-Romano G, et al. Analysis of HLADRB1,DQA1,DQB1 haplotypes in Sardinian centenarians. Exp Gerontol. 2008;43(2):114-8.

30. Naumova E, Pawelec G, Ivanova M, Constantinescu I, Bogunia-Kubik K, Lange A, et al. 14th International HLA and Immunogenetics Workshop: Report on the immunogenetics of aging. Tissue Antigens. 2007;69(SUPPL. 1):304-10.

31. Proust J, Moulias R, Fumeron F, Bekkhoucha F, Busson M, Schmid M, et al. HLA and longevity. Tissue Antigens. 1982;19:168-73.

32. Candore G, Balistreri CR, Colonna-Romano G, Lio D, Listì F, Vasto $\mathrm{S}$, et al. Gender-Related Immune-Inflammatory Factors, Age-Related Diseases, and Longevity. Rejuvenation Res. 2010;13(2-3):292-7.

33. Kraat YJ, Christiaans MHL, Nieman FHM, BergLoonen PM van den, Hooff JP van, Bruggeman CA. Risk factors for cytomegalovirus infection and disease in renal transplant recipients: HLA-DR7 and triple therapy. Transpl Int. 1994;7:362-7.

34. Schrier RD, Freeman WR, Wiley CA, 
Mccutchan JA. Immune Predispositions for Cytomegalovirus Retinitis in AIDS. J Clin Invest. 1987;95:1741-6.

35. Almarri A, Batchelor R. HLA and hepatitis B infection. Lancet. 1994;344:1194-5.

36. Hill AVS. The immunogenetics of human infectious diseases. Annu Rev Immunol. 1998;16(593):593-617.

37. Fernandez-arquero M, Figueredo MA, Maluenda C, Concha EG De. HLA-Linked Genes Acting as Additive Susceptibility Factors in Celiac Disease. Hum Immunol. 1995;300:295-300.

38. Zeliszewski D, Mougenot JF, Dormoy A, Gaudebout C, Tongio MM, Baudon JJ, et al. Reevaluation of the Relative Risk for Susceptibility to Celiac Disease of HLADRB1,-DQA1, -DQB1, -DPB1, and -TAP2 Alleles in a French Population. Hum Immunol. 1995;8859(95).

39. Michalski JP, McCombs CC, Arai T, Elston RC, Cao T, McCarthf CF, et al. HLA-DR, DQ genotypes of celiac disease patients and healthy subjects from the West of Ireland. Tissue Antigens. 1996;47(9):127-33.

40. Kummee P, Tangkijvanich P, Poovorawan Y, Hirankarn N. Association of HLA-DRB1 * 13 and TNF- a gene polymorphisms with clearance of chronic hepatitis $\mathrm{B}$ infection and risk of hepatocellular carcinoma in Thai population. $\mathrm{J}$ Viral Hepat. 2007;14:841-8.

41. Singh R, Kaul R, Kaul A, Khan K. A comparative review of HLA associations with hepatitis B and $\mathrm{C}$ viral infections across global populations. World J Gastroenterol ISSN. 2007;13(12):177087.

42. 42. Bosi I, Ancora G, Mantovani W, Miniero R, Verucchi G, Attard L, et al. HLA DR13 and HCV Vertical Infection. Pediatr Res. 2002;51(6):7469.

43. Yang F, Sun L, Zhu X, Han J, Zeng Y, Nie C, et al. Identification of new genetic variants of HLA - DQB1 associated with human longevity and lipid homeostasis - a cross - sectional study in a Chinese population. Aging (Albany NY). 2017;9(11):2316-33.

44. Doganay L, Fejzullahu A, Katrinli S, Enc FY, Ozturk O, Colak Y. Association of human leukocyte antigen DQB1 and DRB1 alleles with chronic hepatitis $\mathrm{b}$. World J Gastroenterol. 2014;20(25):8179-86.

45. Guoi XJ, Chen E, Zou HJ, Jin L, Mayes MD, Assassp S, et al. Association of HLA-DQBl * 0501 with scleroderma and its clinical features in chinese population. Int $\mathrm{J}$ Immunopathol Pharmacol. 2013;26(3):747-51.

46. Fourati H, Mahfoudh N, Abida O, Kammoun A, Mnif F, Haddouk S, et al. HLA-DRB1 / DQB1 susceptibility for autoimmune polyglandular syndrome type II and III in south of Tunisia. Ann Endocrinol (Paris). 2011;72(3):232-8.

47. Fernandez CA, Smith C, Yang W, Dat M, Bashford D, Larsen E, et al. HLA-DRB1 * 07:01 is associated with a higher risk of asparaginase allergies. Clin TRIALS Obs. 2016;124(8):1266-77.

48. Tashiro R, Id KN, Khor S, Tokunaga K, Fujimura M, Sakata H, et al. Identification of HLA-DRB $1 * 04: 10$ allele as risk allele for Japanese moyamoya disease and its association with autoimmune thyroid disease: A casecontrol study. PLoS One. 2019;1-12.

49. Ricci G, Colombo C, Ghiazza B, Illeni MT. Association between longevity and allelic forms of human leukocyte antigens (HLA): Population study of aged Italian human subjects. Arch Immunol Ther Exp (Warsz). 1998;46(1):31-4.

50. Lio D, Scola L, Crivello A, Candore G, Bonafè $\mathrm{M}$, Cavallone $\mathrm{L}$, et al. Inflammation, genetics, and longevity: further studies on the protective effects in men of IL-10-1082 promoter SNP and its interaction with TNF-alfa-308promoter SNP. J Med Genet. 2003;40:296-9.

51. Cavallone L, Lio D, Scola L, Crivello A, Candore $\mathrm{G}$, Bonafe $\mathrm{M}$, et al. Gender-specific association between -1082 IL-10 promoter polymorphism and longevity. Genes Immun. 2002;30-3.

52. Pes GM, Lio D, Carru C, Deiana L, Baggio G, Franceschi C, et al. Association between longevity and cytokine gene polymorphisms. A study in Sardinian centenarians. Aging Clin Exp Res. 2004;16(3):244-8.

53. Ross OA, Curran MD, Meenagh A, Williams F, Barnett YA, Middleton D, et al. Study of ageassociation with cytokine gene polymorphisms in an aged Irish population. Mech Ageing Dev. 2003;124(2):199-206.

54. Minciullo PL, Catalano A, Mandraffino G, Casciaro M, Crucitti A, Maltese $G$, et al. Inflammaging and Anti-Inflammaging: The Role of Cytokines in Extreme Longevity. Arch Immunol Ther Exp (Warsz). 2016; 64(2):11126.

55. Khabour OF, Barnawi JM. Association of longevity with IL-10- 1082 G/A and TNF- $\alpha-$ $308 \mathrm{G} / \mathrm{A}$ polymorphisms. Int $\mathrm{J}$ Immunogenet. 2010;293-8.

56. Ershler WB. Interleukin-6: A Cytokine for Gerontolgists. J Am Geriatr Soc. 1993;41:17681.

57. Nishimichi N, Kawashima T, Hojyo S. Characterization and expression analysis of a chicken interleukin-6 receptor alpha. Dev Comp Immunol. 2006;30:419-29.

58. Palmeri M, Misiano G, Malaguarnera M, Forte 
GI, Vaccarino L, Milano S, et al. Cytokine serum profile in a group of sicilian nonagenarians. $\mathrm{J}$ Immunoass Immunochem. 2012;33:82-90.

59. Ferrucci L, Corsi A, Lauretani F, Bandinelli $\mathrm{S}$, Bartali B, Taub DD, et al. The origins of age-related proinflammatory state. Blood. 2005;105(6):2294-9.

60. Giovannini S, Onder ÃG, Liperoti ÃR, Russo ÃA, Carter C, Capoluongo E, et al. Interleukin-6, C-Reactive Protein, and Tumor Necrosis FactorAlpha as Predictors of Mortality in Frail, Community-Living Elderly Individuals. J Am Geriatr Soc. 2011;59:1679-85.

61. Terry CF, Loukaci V, Green R, Terry CF, Loukaci V, Green FR. Genes : structure and regulation: Cooperative Influence of Genetic Polymorphisms on Interleukin 6 Transcriptional Regulation Cooperative Influence of Genetic Polymorphisms on Interleukin 6 Transcriptional Regulation *. J Biol Chem. 2000;275:18138-44.

62. Antonicelli R, Olivieri F, Bonafe M, Cavallone L, Spazzafumo L, Marchegiani F, et al. The interleukin-6 $174 \mathrm{G}>\mathrm{C}$ promoter polymorpism is associated with a higher risk of death after an acute coronary syndrome in male elderly patients. Int J Cardiol. 2005;103:266-71.

63. Giacconi R, Cipriano C, Albanese F, Boccoli G, Saba V, Olivieri F, et al. The $2174 \mathrm{G} / \mathrm{C}$ polymorphism of IL-6 is useful to screen old subjects at risk for atherosclerosis or to reach successful ageing. Exp Gerontol. 2004;39:6218.

64. Tonet AC, Karnikowski M, Moraes CF, Gomes L, Karnikowski MGO. Association between the $-174 \mathrm{G} / \mathrm{C}$ promoter polymorphism of the interleukin- 6 gene and cardiovascular disease risk factors in Brazilian older women. Brazilian J Med Biol Res. 2008;41:47-53.

65. Pola R, Gaetani E, Flex A, Aloi F, Papaleo P, Gerardino L, et al. $2174 \mathrm{G} / \mathrm{C}$ interleukin-6 gene polymorphism and increased risk of multiinfarct dementia: a case-control study. Exp Gerontol. 2002;37:949-55.

66. Cederholm T, Persson M,Andersson P, Stenvinkel P, Nordfors L, Madden J, et al. Polymorphisms in cytokine genes influence long-term survival differently in elderly male and female patients. $\mathrm{J}$ Intern Med. 2007;262:215-23.

67. Bonafè M, Olivieri F, Cavallone L, Giovagnetti $\mathrm{S}$, Marchegiani F, Cardelli M, et al. A genderdependent genetic predisposition to produce high levels of IL-6 is detrimental for longevity. Eur J Immunol. 2001;31(8):2357-61.

68. Di D, Vasto S, Capurso C, Christiansen L, Deiana L, Franceschi C, et al. Effect of interleukin-6 polymorphisms on human longevity: A systematic review and meta-analysis. Ageing
Res Rev. 2009;8:36-42.

69. Levine SJ. Tumor Necrosis Factor Alpha (TNF- $\alpha$ ). In G. J. Laurent, \& S. D. Shapiro (Eds.). Encyclopedia of Respiratory Medicine. 2006:307-11.

70. WilsonAG, Symons JA, McDowell TL, McDevitt H, Duff GW. Effects of a polymorphism in the human tumor necrosis factor alpha promoter on transcriptional activation. Proc Natl Acad Sci. 1997;94(April):3195-9.

71. Tuglular S, Berthoux P. Polymorphisms of the tumour necrosis factor a gene at position A 308 and TNFd microsatellite in primary IgA nephropathy. Nephrol Dial Transplan. 2003; 18:724-31.

72. Biggelaar AHJ van den, Craen AJM de, Gussekloo J, Huizinga TWJ, Heijmans BT, Frölich $\mathrm{M}$, et al. Inflammation underlying cardiovascular mortality is a late consequence of evolutionary programming. FASEB J. 2004;17(1):1-17.

73. Mooradian AD, Reed RL, Osterweil D, Scuderi P. Detectable Serum Levels of Tumor Necrosis Elderlv Institutionalized Patients Factor Alpha May Predict Early Mortality in Elderlv Institutionalized Patients. JAGS. 1991;(39):891-4.

74. Roubenoff R, Parise H, Agostino RD, Jacques PF, Wilson PWF, Dinarello CA, et al. Cytokines, Insulin-Like Growth Factor 1, Sarcopenia, and Mortality in VeryOld Community-Dwelling MenandWomen:The Framingham Heart Study. Am J Med. 2003;(11):429-35.

75. Yende S, Tuomanen EI, Wunderink R, Kanaya A, Newman AB, Harris T, et al. Preinfection Systemic Inflammatory Markers and Risk of Hospitalization Due to Pneumonia. Am J Respir Crit Care Med. 2005;177(22):1440-6.

76. Bruunsgaard H, Andersen-ranberg K. Elevated Levels ofTumor Necrosis Factor Alpha and Mortality in Centenarians. Am J Med. 2003;115:278-283.

77. Ushio S, Namba M, Okura T, Hattori K, Nukada $\mathrm{Y}$, Akita $\mathrm{K}$, et al. Cloning of the cDNA for human IFN-gamma-inducing factor, expression in Escherichia coli, and studies on the biologic activities of the protein. J Immunol. 1996;156(11):4274-9.

78. Zanni F, Vescovini R, Biasini C, Fagnoni F, Zanlari L, Telera A, et al. Marked increase with age of type 1 cytokines within memory and effector / cytotoxic CD8+T cells in humans : a contribution to understand the relationship between inflammation and immunosenescence. Exp Gerontol. 2003;38:981-7.

79. Alberti S, Cevenini E, Ostan R, Capri M, Salvioli $\mathrm{S}$, Bucci L, et al. Age-dependent modifications 
of Type 1 and Type 2 cytokines within virgin and memory CD4 $+\mathrm{T}$ cells in humans. Mech ageing Dev. 2006;127:560-6.

80. Lio D, Scola L, Crivello A, Bonafe M. Allele frequencies of $+874 \mathrm{~T}->$ A single nucleotide polymorphism at the first intron of interferongamma gene in a group of Italian centenarians. Exp Gerontol. 2002;37:315-9.

81. 81. Chung HY, Lee EK, Choi YJ, Kim JM, Kim DH, Zou Y, et al. Molecular Inflammation as an Underlying Mechanism of the Aging Process and Age-related Diseases. J Dent Res. 2011;90(7):830-40.

82. Saraiva M, O'Garra A. The regulation of IL-10 production by immune cells. Nat Rev Immunol. 2010;10(3):170-81.

83. Naumova E, Ivanova $M$, Pawelec $G$, Constantinescu I, Bogunia-Kubik K, Lange A, et al. "Immunogenetics of Aging": Report on the activities of the 15th International HLA and Immunogenetics Working Group and 15th International HLA and Immunogenetics Workshop. Tissue Antigens. 2011;77(3):18792.

84. Licastro F, Caldarera CM, Branzi A, Franceschi C, Caruso C. Opposite effects of interleukin 10 common gene polymorphisms in cardiovascular diseases and in successful ageing: genetic background of male centenarians is protective against coronary heart disease. J Med Genet. 2004;790-5.

85. Gm P, Lio D, Carru C, Deiana L, Baggio G, Franceschi C, et al. Association between longevity and cytokine gene polymorphisms . A study in Sardinian centenarians. Aging Clin Exp Res. 2004;16(3):2004.

86. Wang XY, Hurme M, Jylh M, Hervonen A. Lack of association between human longevity and polymorphisms of IL-1 cluster, IL-6, IL-10 and TNF- $\alpha$ genes in Finnish nonagenarians. Mech Ageing Dev. 2001;123(1):29-38.

87. Yoshimura A, Wakabayashi Y, Mori T. Cellular and molecular basis for the regulation of inflammation by TGF- b. J Biochem. 2010;147(6):781-92.

88. Bierie B, Moses HL. Transforming growth factor beta (TGF- $\beta$ ) and inflammation in cancer. Cytokine Growth Factor Rev. 2011;21(1):4959.

89. Carrieri G, Marzi E, Olivieri F, Marchegiani F, Cavallone L, Cardelli M, et al. The G/C915 polymorphism of transforming growth factor betal is associated with human longevity: a study in Italian centenarians. Aging Cell. 2004;3(6):443-8.

90. Forsey RJ, Thompson JM, Ernerudh J, Hurst TL, Strindhall J. Plasma cytokine profiles in elderly humans. Mech Ageing Dev. 2003;124:487-93.

91. Lin Y, Nakachi K, Ito Y, Kikuchi S, Tamakoshi A, Yagyu K. Variations in serum transforming growth factor- $\beta 1$ levels with gender, age and lifestyle factors of healthy Japanese adults. Dis Markers. 2009;27:23-8.

92. Okamoto Y, Gotoh Y, Uemura O, Tanaka S, Ando T. Age-dependent decrease in serum transforming growth factor ( TGF ) -beta 1 in healthy Japanese individuals ; population study of serum TGF-beta 1 level in Japanese. Dis Markers. 2005;21:71-4.

93. Dunn-Walters DK. The ageing human B cell repertoire: A failure of selection? Clin Exp Immunol. 2016;183(1):50-6.

94. Cancro MP, Hao Y, Scholz JL, Riley RL, Frasca D, Dunn-Walters DK, et al. B cells and aging: molecules and mechanisms. Trends Immunol. 2009;30(7):313-8.

95. Zharhary D. Age-related changes in the capability of the bone marrow to generate B cells. J Immunol. 1988;141(6):1863-9.

96. Blanco E, Pérez-andrés M, Arriba-méndez S, Contreras-sanfeliciano T, Criado I, Pelak O, et al. Age-associated distribution of normal B-cell and plasma cell subsets in peripheral blood. J Allergy Clin Immunol. 2018;141(6):2208-19.

97. Riley RL, Blomberg BB, Frasca D. B cells, E2A, and aging. Immunol Rev. 2005;205:30-47.

98. Labrie JE, Sah AP, Allman DM, Cancro MP, Gerstein RM. Bone Marrow Microenvironmental Changes Underlie Reduced RAG-mediated Recombination and B Cell Generation in Aged Mice. J Exp Med. 2004;200(4):411-23.

99. Weksler ME. Immune Senescence : Deficiency or Dysregulation. Nutr Rev. 1995;3-7.

100. Sherwood EM, Blomberg BB, Xu W, Cynthia A, Riley RL, Sherwood EM, et al. Cutting Edge: Senescent BALB/c Mice Exhibit Decreased Expression of $\lambda 5$ Surrogate Light Chains and Reduced Development Within the Pre-B Cell Compartment. J Immunol. 1998;161:44722275.

101. Sherwood EM, Xu W, King AM, Blomberg BB, Riley RL. The reduced expression of surrogate light chains in B cell precursors from senescent $\mathrm{BALB} / \mathrm{c}$ mice is associated with decreased $\mathrm{E} 2 \mathrm{~A}$ proteins. Mech Ageing Dev. 2000;118(1-2):4559.

102. Gibson KL, Wu YC, Barnett Y, Duggan O, Vaughan R, Kondeatis E, et al. B-cell diversity decreases in old age and is correlated with poor health status. Aging Cell. 2009;8(1):18-25.

103. Huang Y, Gauthey L, Michel M, Loreto M, Paccaud M, Pechere J, et al. The Relationship Between Influenza Vaccine-Induced Nonspecific Autoantibody Responses in Healthy Older 
Women. J Gerontol. 1992;47(2):50-5.

104. Wang C, Liu Y, Xu LT, Jackson KJL, Roskin KM, Pham TD, et al. Effects of Aging, Cytomegalovirus Infection, and EBV Infection on Human B Cell Repertoires. J Immunol. 2014;192(2):603-11.

105. Jiang N, He J, Weinstein JA, Penland L, Sasaki $\mathrm{S}$, He XS, et al. Lineage structure of the human antibody repertoire in response to influenza vaccination. Sci Transl Med. 2013;5(171).

106. Ademokun A, Wu YC, Martin V, Mitra R, Sack $\mathrm{U}$, Baxendale $\mathrm{H}$, et al. Vaccinationinduced changes in human B-cell repertoire and pneumococcal IgM and IgA antibody at different ages. Aging Cell. 2011;10(6):922-30.

107. Martin V, Wu YB, Kipling D, Dunn-walters D, Dunn-walters D. Ageing of the B-cell repertoire. Philos Trans R Soc L B Biol Sci. 2015;370(1676):20140237.
108. Romero-steiner S, Musher DM, Cetron MS, Pais LB, Groover JE, Fiore AE, et al. Reduction in Functional Antibody Activity Against Streptococcus pneumoniae in Vaccinated Elderly Individuals Highly Correlates with Decreased IgG Antibody Avidity. Clin Infect Dis. 1999; 29:281-8.

109. Wardemann H. Predominant Autoantibody Production by Early Human B Cell Precursors. Science (80- ). 2003;301(5638):1374-7.

110. Larimore K, McCormick MW, Robins HS, Greenberg PD. Shaping of Human Germline IgH Repertoires Revealed by Deep Sequencing. J Immunol. 2012;189(6):3221-30.

111. Joshi PK et all. Genome-wide meta-analysis associates HLA- DQA1/DRB1 and LPA and lifestyle factors with human longevity. Nat Commun. 2017;1-13. 